\title{
Optimization and Wear Properties for the Composites of Metal Matrix AA8011/Boron Nitride Using Taguchi Method
}

\author{
B. S. Praveen Kumar, ${ }^{1}$ K. R. Shobha, ${ }^{2}$ Manoj Kumar Singh, ${ }^{3}$ Moti Lal Rinawa, ${ }^{4}$ \\ S. Madhavarao $\mathbb{D D}^{5}{ }^{5}$ Gurumeet C. Wadhawa, ${ }^{6}$ Tahani A. Alrebdi, ${ }^{7}$ and David Christopher ${ }^{8}{ }^{8}$ \\ ${ }^{1}$ Department of Mechanical Engineering, Presidency University, Bengaluru, Karnataka 560064, India \\ ${ }^{2}$ Department of Electronics and Telecommunication Engineering, Ramaiah Institute of Technology, Bengaluru, \\ Karnataka 560054, India \\ ${ }^{3}$ Department of Mechanical Engineering, Faculty of Engineering and Technology, MJP Rohilkhand University Bareilly, \\ UP-243006, India \\ ${ }^{4}$ Department of Mechanical Engineering, Government Engineering College Jhalawar, Rajasthan 326023, India \\ ${ }^{5}$ Department of Mechanical Engineering, Sagi Rama Krishnam Raju Engineering College, Bhimavaram, \\ Andhra Pradesh 534204, India \\ ${ }^{6}$ Department of Chemistry, Karmaveer Bhaurao Patil College, Vashi, Navi Mumbai, India \\ ${ }^{7}$ Department of Physics, College of Science, Princess Nourah Bint Abdulrahman University, P.O. Box 84428, \\ Riyadh 11671, Saudi Arabia \\ ${ }^{8}$ Department of Mechanical Engineering, College of Engineering, Wolaita Sodo University, Ethiopia
}

Correspondence should be addressed to David Christopher; david.santosh@wsu.edu.et

Received 28 November 2021; Revised 4 January 2022; Accepted 6 January 2022; Published 8 February 2022

Academic Editor: Palanivel Velmurugan

Copyright (c) 2022 B. S. Praveen Kumar et al. This is an open access article distributed under the Creative Commons Attribution License, which permits unrestricted use, distribution, and reproduction in any medium, provided the original work is properly cited.

\begin{abstract}
In automotive and aircraft design, a new emerging material known as AA8011 metal matrix composite has earned a place for the reason that it is extremely durable and extremely hard. Newer composite variants were created and selected because of the demand for improved tribological performance. This study's objective is to find out how an AA8011-Boron Nitride metal matrix composite (MMC) wears out under different loads and sliding speeds. AMMC fortified with Boron Nitride particles are created using the powder metallurgy route and contain weight fractions ranging from $10 \%$ to $15 \%$ of the AA8011 and $37 \mu \mathrm{m}$ Boron Nitride particles. The material is made in an electric melting furnace through a stir casting procedure. Next, the materials are tested to see how long they will last in a tribotester set up like this: a block on a roller. With a controlled experimentation strategy, wear data can be collected using the L27 Taguchi method. Dry sliding wear of composites is controlled by four parameters: Boron Nitride substance, load-bearing capacity, slid speed, and sliding time. An analysis of variance is used to determine their effects. Sliding speed, friction, and normal load all have an effect on how much dry sliding wear occurs. In addition, the least amount of wear is obtained by combining the four controlling parameters optimally.
\end{abstract}

\section{Introduction}

MMCs synthesized from aluminum alloy have excellent mechanical properties largely owing to the use of ceramic abrasive grit like Boron Nitride. Composites like these are strong and lightweight while also having good wear resistance and weight reduction properties, which makes them an excellent structural material. These types of applications spark metal matrix composite wear behavior research [1]. Composites can be made using a variety of methods, but the most common is powder metallurgy, squeeze casting, and stir casting [2-7]. As a rule, scientists believe that between $0 \%$ and $30 \%$ of the volume should be reinforced with silicon carbide. Some researchers have used higher volume fractions of $60 \%$ and $10 \%-40 \%[8,9]$. Boron Nitride $(\mathrm{BN})$, a refractory material composed of boron-nitrogen 
covalent bonds, was widely used. After diamond, BN is the second hardest material known. Its abrasive properties make it ideal for tools used in cutting and grinding operations. Tests for wear are carried out by altering sliding speed and applied load. Al-Boron Nitride MMC's abrasive wear behavior was investigated by changing $5 \%$ to $20 \%$ of Boron Nitride reinforcement volume, with particle sizes ranging from 10, 27 , and $43 \mu \mathrm{m}$. Due to the wide range of materials studied, it was found that as the size of the abrasive particle increases, the wear rates increase but decrease as a percentage of the total volume increases. The wear performance of an Al$\mathrm{Mg}-\mathrm{Cu}$ alloy fortified with $\mathrm{BN}$ particles was analysed by [10]. Alloy wear resistance was significantly improved by mixing in a small amount of Boron Nitride (BN). Using the same methodology, [11] investigated how people choose to dress. An aluminum alloy reinforced with $\mathrm{BN}$ particles underwent high-speed wear testing. Composite material was created by using three different powdered metallurgy techniques, each with its own blend of densities and sizes of ferro cement particles. Load and speed were adjusted during the wear studies. When interpreting sliding distance speed, wear rates rise. Particle reinforcement has been considered by most researchers, while reinforcement has been used by others $[4,5,12]$. The material's wear behavior was studied by who used an $\mathrm{Al}$ alloy with a whisker content of $15 \%$ by volume of $\mathrm{BN}$. As counter material, a steel ball was used to perform the wear tests on an oscillating wear tester. The Al-BN composite outperformed the aluminum alloy in order to wear resistance, according to the results of the tests. The same team of researchers used Al-Mo-BN composite in another wear study [5]. As $\mathrm{Al}$ abrasive particle size increased in the test, the wear rate increased as well, as reported by for another abrasive. Aluminum's abrasion resistance is increased by incorporating Boron Nitride. Al-5\% BN and $\mathrm{Al}-10 \% \mathrm{BN}$ examined the impact load on the wear properties of the substances. As reinforcement particle volume fraction increased, the wear rate grew as well, but as applied load increased, the wear rate decreased. It was discovered by that heating the Al-BN MMC synthesized by fortifying 15 vol \% $\mathrm{BN}$ in $\mathrm{Al}$ alloy increased the material's hardness, which in turn increased the material's fretting resistance to deterioration with time. Aluminum 2024 alloy was used to reinforce $15 \% \mathrm{BN}$ and $15 \%$ Mo to create the composite. Dry and lubricated conditions were used for the wear tests. Lubricants included liquid paraffin and sulphurized olefin. Adding molybdenum powder improves the alloy's wear resistance, according to the research. In addition, the presence of lubricants reduces wear rates. Tests of dry sliding wear on reinforced Al-BN composites with BN whiskers were performed by [12]. The $\mathrm{BN}$ whisker volume fraction ranged from $0 \%$ to $16 \%$. The wear rates gradually decrease in proportion to the $\mathrm{BN}$ volume concentration whisker reinforcement in the aluminum alloy increases.

To better understand the wear behavior of the composite, the impact of the load and temperature that is being applied was investigated [13]. They discovered that as load increases, the contact temperature rises to over $1500^{\circ} \mathrm{C}$, increasing the material's wear rate. When the weight of the cargo and the rate at which it slides increase, the wear rate increases, but when the wear resistance improves due to heat treatment, the researchers found, as reported by [14]. The effect of the reinforcement BN volume fraction was investigated by [15]. Tests on different loads and sliding speeds were conducted on a volume fraction range of $1 \%-5 \%$. An increase in the silicon carbide volume concentration, however, load and speed of sledding rise even as the rate of degradation decreases.

There has been a great deal of investigation into process variables such as weight fractions, ultimate force, sliding velocity, and validation particle size. Researchers have experimented with a variety of process parameters to better understand how the composite material wears over time. When it came to Al-BN composite wear, Rao and Das looked at how much matrix alloy mattered [16]. Three different matrix alloys were used to cast Al-BN composites with $10 \%, 15 \%$, and $25 \% \mathrm{BN}$ affirmation. According to the wear tests, the composites with the greatest copper percentage wore out faster than the others. There was a significant difference in fatigue life between the zinc-rich alloy and the others. The wear rate of all composites was reduced by adding $\mathrm{BN}$ reinforcement. [17] carried out a study on the fabrication of Al-BN using two different melting methods. $0 \%-20 \%$ volume fraction was selected for the material fabrication. The results of the wear results of the experiment showed that a percentage of total volume of $\mathrm{BN}$ was fortified. The rate of wear dropped as the volume increased. Resistance to abrasion of materials fabricated by the turbulence method decreases more slowly than those of materials fabricated by the dilution method as the density of $\mathrm{BN}$ is increasing, as is the force applied. Other researchers $[18,19]$ have conducted similar research on the Al-BN composite structural characteristics.

Although many studies have been done on AA8011-BN particulate composite's wear behavior, none has focused on optimizing process parameters for the lowest possible wear response, as can be seen from the review of existing literature. The Taguchi method design with four control factors, namely, the weight percentage of structural steel, the forces acting, sliding velocity, and duration, is currently being studied to optimize Al-BN composite wear behavior. The multitribotester with a component on pulley arrangement is used to conduct the wear test. To minimize wear and tear, the trial results are analysed to find the best process parameter combination possible. The Taguchi method confirms the optimal process parameter combination through a confirmation test. Operating factors are examined to see how they interact with material wear behavior using the ANOVA.

\section{Taguchi Method}

Elevated systems based on OA observations with very small variation can be designed $[20,21]$ using the Taguchi method to identify the optimum control performance. For the first time, an integrated approach that considers quality, appearance, and computational complexity all at once is presented. This method can be used in conjunction with design of experiments (DOE) [22] and process deterministic tuning to achieve the expected outcomes. Long-established 
processes for research methodology concentrate on the process achievability properties. Rather than looking at averages like in conventional statistical analysis, this method examines how variations affect process quality characteristics. As a result of the Taguchi method, changes in uncontrolled or noise factors have no effect on the process's performance (durability Taguchi proposes that off-line monitoring can be achieved with proper parameter design during the "parameter design" phase). Standard operating procedures (OAs) helped him figure out how many tests are required for two or more parameters to have an effect on the overall fluctuation of a particular system or project. Using a small sample size, it explores the design philosophy space by determining all parameter effects and several interactions using OA. To minimize the objective function while also meeting all constraints, these data are used to predict an optimal design parameter combination. By determining parameter trends and noise sensitivities, the Taguchi method not only locates a near-optimal objective function but also aids in robust design.

When using the Taguchi method's parameter design phase, the following steps are usually included:

(1) Identify the experiment's goal; identify the quality characteristic's measurement systems

(2) Determine the variables that may have an impact on the quality characteristic, the magnitude of those variables, and how they might interact

(3) Determine which OA should be used and assign the variables to it based on their importance

(4) The test described by the OA trials should be carried out

(5) For figuring out which variables are considered significant from a statistical perspective and what the best levels are of variables by analysing experimental data's $\mathrm{S} / \mathrm{N}$, factor effects, and ANOVA ratios

Because of the OA, a series among well tests is required (less observational runs). As predictive control functions, the Taguchi method measures statistical performance using $(\mathrm{S} / \mathrm{N})$ ratios, which are exponential operations of the expected outcome. To calculate the Sound-to-Noise ratio, the mean and fluctuation must be considered. The standard deviation is used to calculate the exponent (noise).

Impact extent of the ratio is dependent on the superiority performances of the creation, or the method under consideration depends on the product or process under consideration. $\mathrm{S} / \mathrm{N}$ ratios are classified into three groups:

(i) Lower the better (LB)

(ii) Higher the better ( $\mathrm{HB})$

(iii) Nominal the best (NB)

In order to get the highest possible $\mathrm{S} / \mathrm{N}$ ratio, use the parameter level combination that minimizes noise. It is necessary to have the $\mathrm{LB}$ characteristic to reduce the wear.
TABle 1: Chemical composition.

\begin{tabular}{lccccc}
\hline Elements & $(\%)$ & Elements & $(\%)$ & Elements & $(\%)$ \\
\hline Boron & $10.0-13.0$ & $\mathrm{Mn}$ & 0.5 & $\mathrm{Ti}$ & 0.2 \\
$\mathrm{Fe}$ & 0.6 & $\mathrm{Zn}$ & 0.1 & $\mathrm{~Pb}$ & 0.1 \\
$\mathrm{Cu}$ & 0.1 & $\mathrm{Mg}$ & 0.1 & $\mathrm{Ni}$ & 0.1 \\
$\mathrm{AA} 8011$ & Rest & & & & \\
\hline
\end{tabular}

If the process parameter is significant, we perform an ANOVA to see how much variance there is in the data [23]. Process parameter combinations can be predicted using the $\mathrm{S} / \mathrm{N}$ ratio and ANOVA. Finally, a confirmation experiment verifies the best process parameters.

\section{Experimental Details}

3.1. Material Processing. AA8011 with 400 mesh boron particles (size $37 \mathrm{~m}$ ) is used as a matrix metal for the production process. Between $10 \%$ and $15 \%$ of the weight is reinforced (also called the volume fraction of reinforcement). Table 1 displays the sequence material's chemical components. Liquid metal stir casting is used to make the composite material because it is quick and easy to do. When the small AA8011 ingots are melted in an electric resistance furnace, three weight percent $\mathrm{Mg}$ is added to the liquid metal and reduces the matrix alloy's surface energy while strengthening the bond with the reinforcing particles (wetting angle). Incorporating pure magnesium improves the flowability of the liquid metal. Particles are heated to $900-950^{\circ} \mathrm{C}$ for $3-4$ hours to oxidize their surfaces before being mixed with the silicon carbide in the liquid AA8011. The melt is mechanically stirred using an aerator made of stainless steel and boron particles that are still hot in the liquid. It is heated to $800^{\circ} \mathrm{C}$ and stirred at $450-550 \mathrm{rpm}$ to create the composite. The slurry is then deposited into a boron mound. After that, it was time to cool down the substance and a variety of machining processes are employed to prepare test samples for wear.

3.2. Design of Experiment. To model and analyse how process variables affect response variables, the DOE technique can be utilized. Response variables make use of system parameters, also referred to as design factors, which are unknown functions. During the course of an experiment, variables such as design factors and control factors are changed. The friction coefficient of AA8011-boron composites has been found to be affected by many tribological process parameters in the literature, as was the case in this research.

However, all process parameters cannot be taken into account in a single study. Volume fraction of reinforcement $(V)$, applied load $(L)$, sliding speed $(S)$, and sliding time $(T)$ were selected as the control parameters for the current study of AA 8011-boron wear behavior. As you can see in Table 2, the various design factors are listed along with their corresponding values. There are three levels of consideration for each parameter in order to avoid any nonlinear effects. Wear is treated as a response variable because it needs to be optimized. 
TABLE 2: Design factors with levels.

\begin{tabular}{|c|c|c|c|c|}
\hline \multirow{2}{*}{ Design factors } & \multirow{2}{*}{ Unit } & \multicolumn{3}{|c|}{ Levels } \\
\hline & & 1 & 2 & 3 \\
\hline Volume fraction of reinforcement $(V)$ & $\%$ by weight & 7.5 & 10 & 12.5 \\
\hline Load $(L)$ & $\mathrm{N}$ & 75 & 100 & 125 \\
\hline Time $(T)$ & MIN & 30 & 40 & 50 \\
\hline Speed $(S)$ & RPM & 200 & 220 & 240 \\
\hline
\end{tabular}

$i=$ initial condition.

TABLE 3: L27 orthogonal array with design factors.

\begin{tabular}{|c|c|c|c|c|c|c|c|c|c|c|c|c|c|}
\hline Trial & 1 & 2 & 3 & 4 & 5 & 6 & 7 & 8 & 9 & 10 & 11 & 12 & 13 \\
\hline Number & $V$ & $L$ & $V \times L$ & $V \times L$ & $S$ & $V \times S$ & $V \times S$ & $L \times S$ & $T$ & - & $L \times S$ & - & - \\
\hline 1 & 1 & 1 & 1 & 1 & 1 & 1 & 1 & 1 & 1 & 1 & 1 & 1 & 1 \\
\hline 2 & 1 & 1 & 1 & 1 & 2 & 2 & 2 & 2 & 2 & 2 & 2 & 2 & 2 \\
\hline 3 & 1 & 1 & 1 & 1 & 3 & 3 & 3 & 3 & 3 & 3 & 3 & 3 & 3 \\
\hline 4 & 1 & 2 & 2 & 2 & 1 & 1 & 1 & 2 & 2 & 2 & 3 & 3 & 3 \\
\hline 5 & 1 & 2 & 2 & 2 & 2 & 2 & 2 & 3 & 3 & 3 & 1 & 1 & 1 \\
\hline 6 & 1 & 2 & 2 & 2 & 3 & 3 & 3 & 1 & 1 & 1 & 2 & 2 & 2 \\
\hline 7 & 1 & 3 & 3 & 3 & 1 & 1 & 1 & 3 & 3 & 3 & 2 & 2 & 2 \\
\hline 8 & 1 & 3 & 3 & 3 & 2 & 2 & 2 & 1 & 1 & 1 & 3 & 3 & 3 \\
\hline 9 & 1 & 3 & 3 & 3 & 3 & 3 & 3 & 2 & 2 & 2 & 1 & 1 & 1 \\
\hline 10 & 2 & 1 & 2 & 3 & 1 & 2 & 3 & 1 & 2 & 3 & 1 & 2 & 3 \\
\hline 11 & 2 & 1 & 2 & 3 & 2 & 3 & 1 & 2 & 3 & 1 & 2 & 3 & 1 \\
\hline 12 & 2 & 1 & 2 & 3 & 3 & 1 & 2 & 3 & 1 & 2 & 3 & 1 & 2 \\
\hline 13 & 2 & 2 & 3 & 1 & 1 & 2 & 3 & 2 & 3 & 1 & 3 & 1 & 2 \\
\hline 14 & 2 & 2 & 3 & 1 & 2 & 3 & 1 & 3 & 1 & 2 & 1 & 2 & 3 \\
\hline 15 & 2 & 2 & 3 & 1 & 3 & 1 & 2 & 1 & 2 & 3 & 2 & 3 & 1 \\
\hline 16 & 2 & 3 & 1 & 2 & 1 & 2 & 3 & 3 & 1 & 2 & 2 & 3 & 1 \\
\hline 17 & 2 & 3 & 1 & 2 & 2 & 3 & 1 & 1 & 2 & 3 & 3 & 1 & 2 \\
\hline 18 & 2 & 3 & 1 & 2 & 3 & 1 & 2 & 2 & 3 & 1 & 1 & 2 & 3 \\
\hline 19 & 3 & 1 & 3 & 2 & 1 & 2 & 2 & 1 & 3 & 2 & 1 & 3 & 2 \\
\hline 20 & 3 & 1 & 3 & 2 & 2 & 3 & 3 & 2 & 1 & 3 & 2 & 1 & 3 \\
\hline 21 & 3 & 1 & 3 & 2 & 3 & 1 & 1 & 3 & 2 & 1 & 3 & 2 & 1 \\
\hline 22 & 3 & 2 & 1 & 3 & 1 & 2 & 2 & 2 & 1 & 3 & 3 & 2 & 1 \\
\hline 23 & 3 & 2 & 1 & 3 & 2 & 3 & 3 & 3 & 2 & 1 & 1 & 3 & 2 \\
\hline 24 & 3 & 2 & 1 & 3 & 3 & 1 & 1 & 1 & 3 & 2 & 2 & 1 & 3 \\
\hline 25 & 3 & 3 & 2 & 1 & 1 & 2 & 2 & 3 & 2 & 1 & 2 & 1 & 3 \\
\hline 26 & 3 & 3 & 2 & 1 & 2 & 3 & 3 & 1 & 3 & 2 & 3 & 2 & 1 \\
\hline 27 & 3 & 3 & 2 & 1 & 3 & 1 & 1 & 2 & 1 & 3 & 1 & 3 & 2 \\
\hline
\end{tabular}

The Taguchi technique OA is measured by counting the trials required to calculate the ideal durability for AA8011boron MMC. In order to investigate both their direct effects and interactions, the orthogonal array allows for simultaneous changes in all process parameters. This experiment makes use of the L27 OA. The number of DOF in an orthogonal array determines its use.

The L27 OA has 27 rows and a degree of freedom of 26. It also has 13 columns and three levels. The DOF increases to four when the design factors interact in a two-way fashion, with each having two degrees of freedom. As a result, there are 20 possible outcomes from this experiment. The Taguchi method dictates that all of the OA used in the experiment must have overall degrees of freedom that are approximately equal to the total DOFs required for the investigation. The L27 OA was selected in this instance. Volume fraction $(V)$, load $(L)$, sliding speed $(S)$, and time $(T)$ are all listed in separate columns $(D)$. The two-way interactions of the first three factors are broken down into six columns, while the errors are broken down into three columns.

As shown in Table 3, a wide range of critical parameters interacts in an OA. The values in the cells represent the 


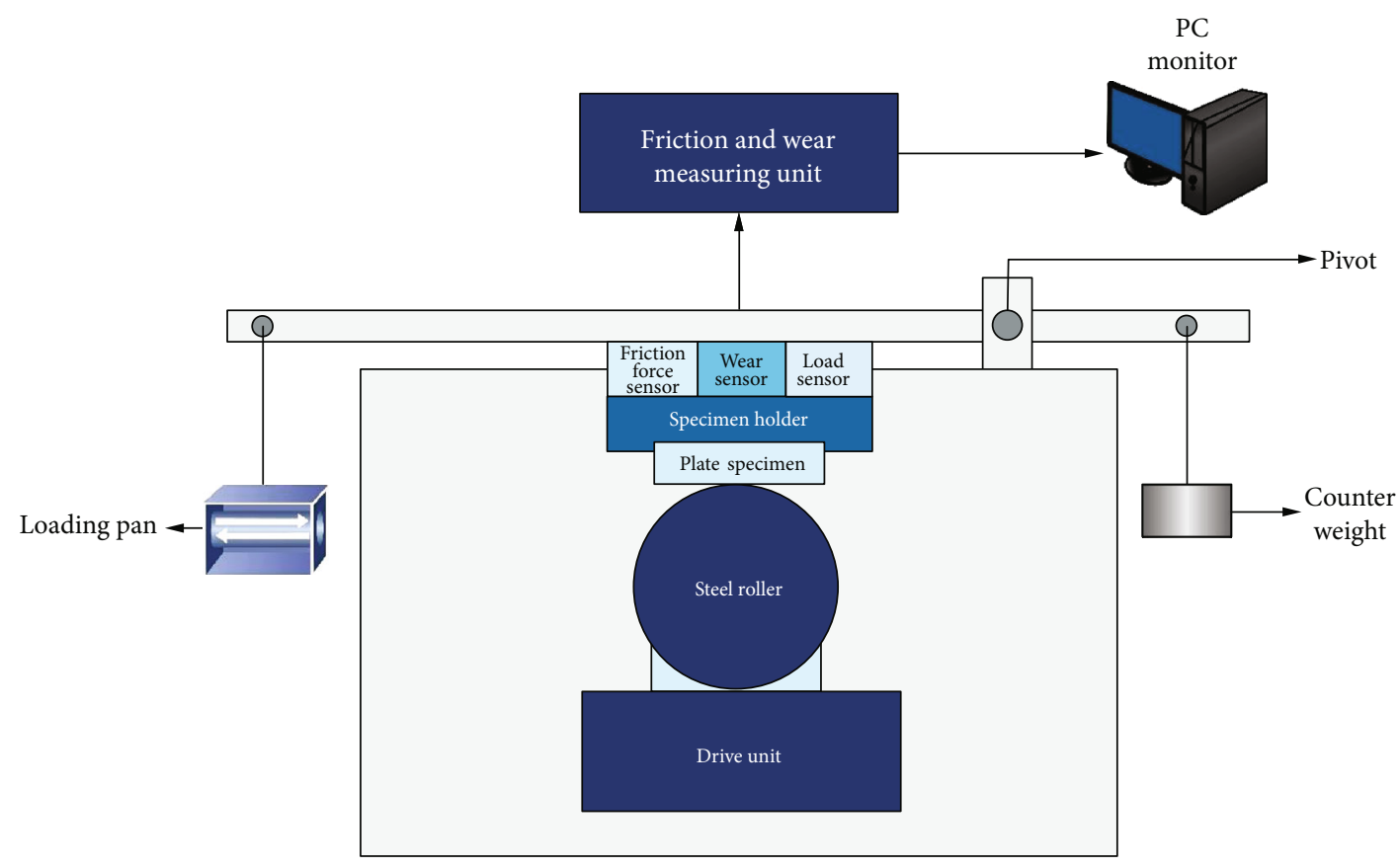

Figure 1: Multitribotester wear testing schematic diagram.

factor settings used during each experimental run, which are represented by the rows. When it comes to the four main factors $(V, L, S$, and $T)$, the cell values indicate their levels $(1,2$, or 3$)$. The levels of the main factors affecting the respective cell values are combined in interactions (2 distinct fields in sections for a chemical bonding). $V$ and $L$ take up sections 3 and 4, as well as trial no. 1's field of interactions have a value of 1 in column 3 and a value of 1 in column 4. In other words, the product of $V$ and $L$ has a level 1 value of 11 , indicating it is a level 1 combination. In columns 3 and 4 , there are nine such combinations for the $V$ and $L$ interaction $(11,22,33,12,21,23,32,13$, and 31). Other terms of interaction follow a similar procedure. Because of these elements of the design that can be manipulated $(V, L, S$, and $T)$, the experimental run is not affected by the interactions. In ANOVA, the percentage contribution of the cells in the interaction and error columns to the overall effect is calculated using the cell values. If the full factorial design were used in this case, there would be $3^{4}=81$ runs to take into account even the four most important factors. When using the L27 OA, you will only have to run it 27 times instead of the full factorial design's 144 times. The array is orthogonal, meaning that all of the factor levels in the design are equally important.

3.3. Wear Tests. The multitribotester TR25 roller is used to conduct the wear tests in a block (Figure 1). In this experiment, AA 8011-boron wear behavior is examined in a dry, nonlubricated condition at $300^{\circ} \mathrm{C}$ and an approximate humidity of $80 \%$. It is a $65 \mathrm{HRc}$ steel roller that presses the AA8011-boron samples against. The roller's diameter is 60 millimetres, its thickness is 60 millimetres, and its material is EN32 steel. The spinning wheel acts as a quasimaterial for the test, while the test specimen is a static plate. The upper edge specimen is subjected to a normal load using the 1:5 load-carrying piston. A loading pan hangs from the lever's other end, close to normal load sensing element, where the dead weights are hung. We can use a linear voltage resistance transducer to figure out the wear rate in terms of distance travelled. Using a wear displacement sensor, you can find out how much the loading lever sways as a result of specimen plate and counterface wear happening at once. Normal wear behavior is uttered in terms of wear volume, whereas wear is currently measured in terms of displacement; it should be noted. Displacement results are compared to weight loss to determine the wear measurement precision. The results show a nearly relational structure for the current investigation's range of test factors.

\section{Results and Summary}

An AA8011-BN particulate MMC is subjected to the Taguchi technique in order to reduce wear. Four control parameters were used in the investigation: fortified volume fraction, force applied, sliding speed, and experiment duration. When evaluating system performance, wear and tear are used as a yardstick. Figures 2(a) and 2(b) reveal the SEM images of AA8011 and AA8011/BN. SEM images show the uniform distribution of $\mathrm{BN}$.

4.1. Signal-to-Noise Ratio Analysis. The Taguchi technique reduces wear in an AA8011-BN particulate MMC. It was decided that the reinforcement volume fraction would be tested along with other experimental parameters like applied load, sliding speed, and duration. Depending on 


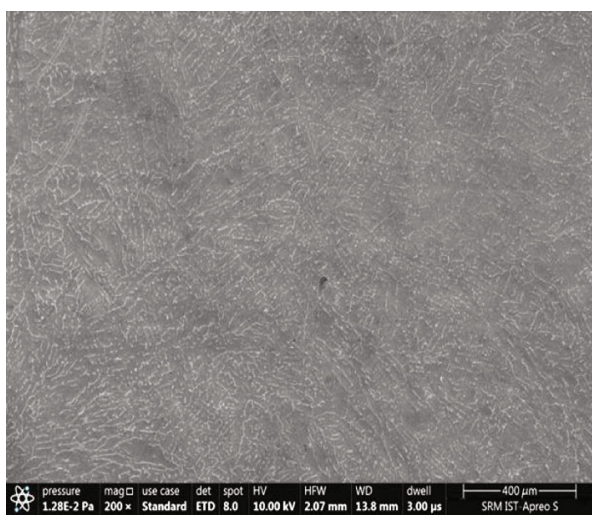

(a)

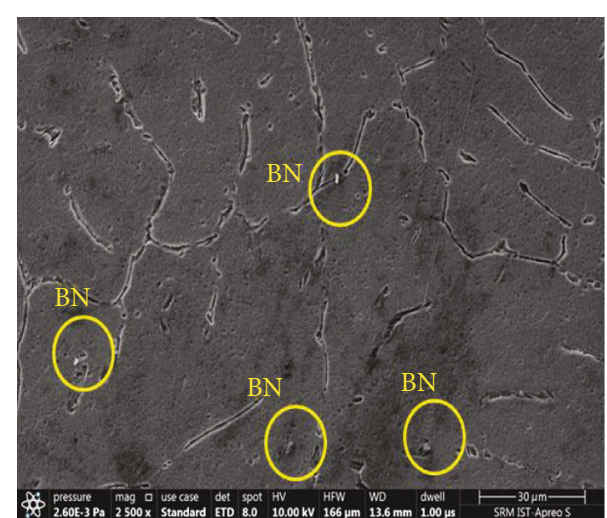

(b)

Figure 2: $(a, b)$ SEM images of AA8011 and AA8011/15 wt\% BN.

TABLE 4: Results of wear experiments with a S/N ratio.

\begin{tabular}{|c|c|c|}
\hline Exp. No. & Wear $(\mu \mathrm{m})$ & $\mathrm{S} / \mathrm{N}$ ratio \\
\hline 1 & 63.08 & -37.06 \\
\hline 2 & 82.14 & -39.39 \\
\hline 3 & 86.38 & -39.84 \\
\hline 4 & 78.4 & -38.99 \\
\hline 5 & 86.69 & -39.87 \\
\hline 6 & 90.92 & -40.29 \\
\hline 7 & 86.48 & -39.85 \\
\hline 8 & 92.17 & -40.41 \\
\hline 9 & 115.01 & -42.36 \\
\hline 10 & 49.99 & -35.00 \\
\hline 11 & 67.41 & -37.65 \\
\hline 12 & 80.02 & -39.17 \\
\hline 13 & 69.96 & -37.98 \\
\hline 14 & 80.18 & -39.19 \\
\hline 15 & 87.00 & -39.91 \\
\hline 16 & 74.56 & -38.54 \\
\hline 17 & 86.68 & -39.87 \\
\hline 18 & 97.13 & -40.88 \\
\hline 19 & 37.54 & -32.44 \\
\hline 20 & 48.43 & -34.72 \\
\hline 21 & 67.54 & -37.67 \\
\hline 22 & 44.08 & -33.88 \\
\hline 23 & 58.8 & -36.44 \\
\hline 24 & 71.84 & -38.22 \\
\hline 25 & 56.85 & -36.14 \\
\hline 26 & 71.57 & -38.18 \\
\hline 27 & 80.29 & -39.20 \\
\hline
\end{tabular}

the amount of wear, we can infer how well the system will perform.

$$
\frac{S}{N}=-10 \log \left(\frac{\Sigma y^{2}}{n}\right) .
$$

Here, $y$ is the experimental data and $n$ is the number of experiments.

Table 4 summarizes the $\mathrm{S} / \mathrm{N}$ ratios and the experimental outcomes of wear tests. It is possible to distinguish between the effects of each control factor because the experiment's design is orthogonal. As an illustration, consider factor $V$ 's average $\mathrm{S} / \mathrm{N}$ ratio (Vol percent), the $\mathrm{S} / \mathrm{N}$ ratios can be averaged to arrive at this value from experiments 1 through 9, 10 through 18, and 19 through 27, for example. Sound-toNoise ratios for other variables can be calculated in the same way. There is a response table that shows the average of every controllable factor's $\mathrm{S} / \mathrm{N}$ ratio (Table 5 ). The average $\mathrm{S} / \mathrm{N}$ ratio for each of the 27 tests is planned and shown separately in the following table. Minitab is used to perform all the calculations. It is decided where to place each parameter based on how much of a difference there is between their average values (the highest one) and the lowest one (the lowest one). Because of the high delta value of the volume fraction, it receives the highest possible ranking: 1 (vol \%). The $\mathrm{S} / \mathrm{N}$ ratio has a significant impact on the results, as indicated in Figure 3. Figure 4 indicates the plots of the interaction between the applied load volume fractions and the sliding speed. The most important factor affecting a material's wear behavior with the steepest inclination line.

Using the main effects plot, it is easy to see that $V$ is the utmost critical parameter, with other factors such as load and speed having an impact on how quickly the MMC wears out. The interaction plots can be studied using the nonparallelism of parameter effects. The parameters are highly interdependent if the interaction plot's lines are not parallel or intersecting. The interaction between lines is minimal or nonexistent if they are parallel to one another. There are nearly parallel lines in the plots shown in Figure 3. As a result, the parameters have very little interaction with one another. AA8011-boron particulate composites' wear characteristics are heavily influenced by the $V, S$, and $L$. Conclusion: with V3L1S1T1, which combines the highest reinforcement volume fraction with the lowest $L, S$, and $T$, the mean Sound-to-Noise ratio can be maximized while wear is minimized. 
TABLE 5: ANOVA table for wear.

\begin{tabular}{|c|c|c|c|c|c|}
\hline Source & Degrees of freedom & Sum of squares & Mean squares & Variance ratio $(F)$ & Contribution \% \\
\hline Volume fraction & 2 & 52.305 & 28.928 & 119.6 & 39.50 \\
\hline Load & 2 & 27.105 & 13.859 & 60.8 & 19.42 \\
\hline Speed & 2 & 41.672 & 19.782 & 90.4 & 29.62 \\
\hline Time & 2 & 0.568 & 0.342 & 1.42 & 0.38 \\
\hline Volume fraction $\times$ load & 4 & 0.989 & 0.301 & 0.89 & 0.71 \\
\hline Volume fraction $\times$ speed & 4 & 3.682 & 0.862 & 2.89 & 2.85 \\
\hline Load $\times$ speed & 4 & 2.789 & 0.586 & 2.31 & 1.62 \\
\hline Error & 6 & 1.289 & 0.289 & & 0.92 \\
\hline Total & 26 & 142.238 & & & 100 \\
\hline
\end{tabular}

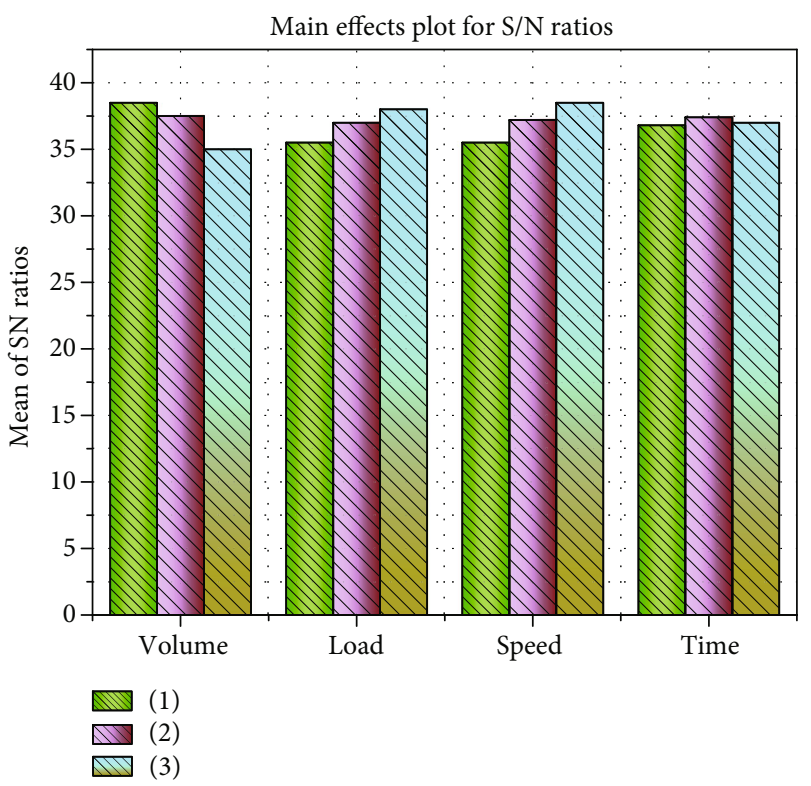

FIgure 3: Main effect plot for $\mathrm{S} / \mathrm{N}$ ratios.

Figure 4 shows different process parameters have an impact on the composite's wear. When the Sound-to-Noise ratio is low, the wear is minimal, while when the $\mathrm{S} / \mathrm{N}$ ratio is high, the wear is substantial. Load applied and sliding speed both increase at the same time as reinforcement content increases. Sliding time is critical, but it barely affects wear. As the volume fraction of fortified boron particulates rises, the composite's roughness improves wear resistance. Boron Nitride particles also serve as a protective shield against the corrosive abrasive effects of wear debris. Application load increases increase the stress on surfaces causing surface damage, which in turn causes more wear. There are more asperity junctions formed and broken when sliding speed increases. With a rise in sliding time comes a small rise in wear at first, but after that, wear remains constant. Asperities became smoother after initial contact, which may have contributed to this.

4.2. Analysis of Variance. With the intervention of ANOVA, scientists can draw some important conclusions from exper- imental data. It is possible to determine the importance of a factor or the interaction between them by using this method. It is possible to calculate each factor's commitment to phenotypic variance of a response by breaking it down into component parts. ANOVA is used to determine which factors and interactions have the greatest influence on a set of performance indicators. As can be seen in Table 5, the AA8011-BN metal matrix composites have a high wear resistance. The $F$-ratio equates the stagnation mean square with the regression mean square error and can be calculated using ANOVA. F-ratio compares the variance caused by the effect of a factor to that caused by an error. The variance ratio is also referred to as the $F$-ratio. If the variance of one variable is greater than the variation of all other terms in the error term, then the experiment's findings are significant. The factor is significant as long as the calculated $F$ ratio exceeds the tabulated $F$-ratio value. It is important to note that as $F$ gets higher, the parameter gets more important ANOVA table that can be used to compare the relative importance of various variables. For example, a 99.5\% confidence level shows that parameter $V$, or volume fraction, influences wear performance, while factors $L$ and $S$ are also important within a given test level. The composite's wear property is unaffected by sliding time or parameter interaction.

4.3. Confirmation Test. A possible improvement would be to determine what level of testing parameters work best and then perform validation tests on those results. The estimated Sound-to-Noise ratio can be calculated as follows using the ideal validation configuration level:

$$
\eta^{\wedge}=\eta_{m}+\sum_{i=1}^{0}\left(\eta_{i}-\eta_{w}\right)
$$

where $\eta_{m}$ is the mean $\mathrm{S} / \mathrm{N}$ ratio and $\eta_{i}$ is the optimum parameter setting for testing and the quantum of important criteria for the creative process that have a significant impact on AA8011-BN metal matrix composite wear behavior. Table 6 compares the predicted wear with the actual wear under optimal conditions (as measured by actual wear). It is easy to see that the estimated and experimental results agree quite well. The Sound-to-Noise ratio 


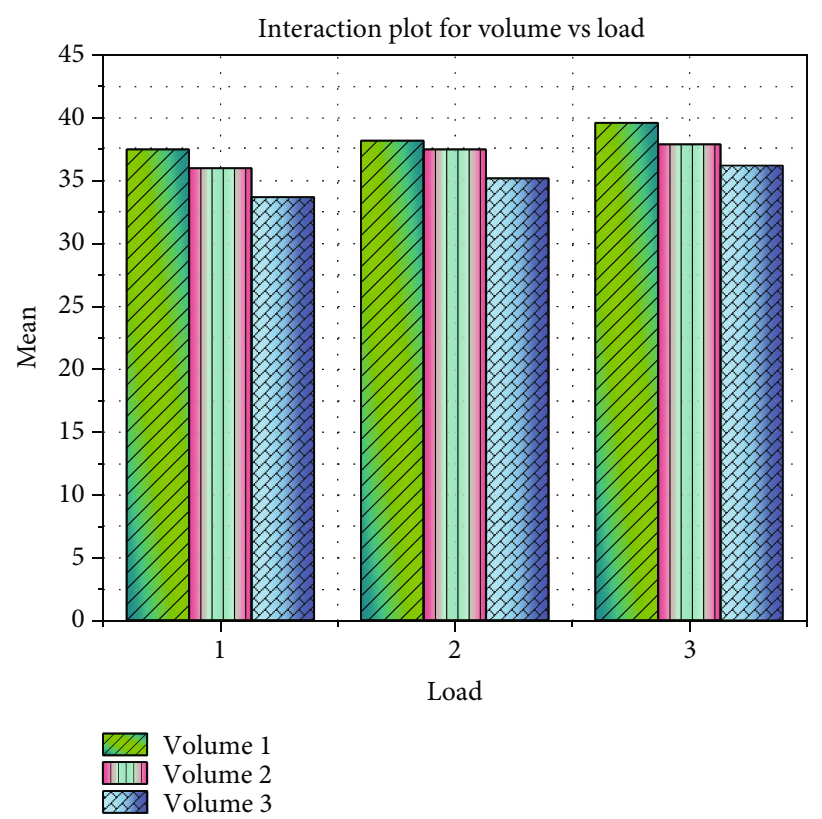

(a) Interaction plot for volume fraction vs. load

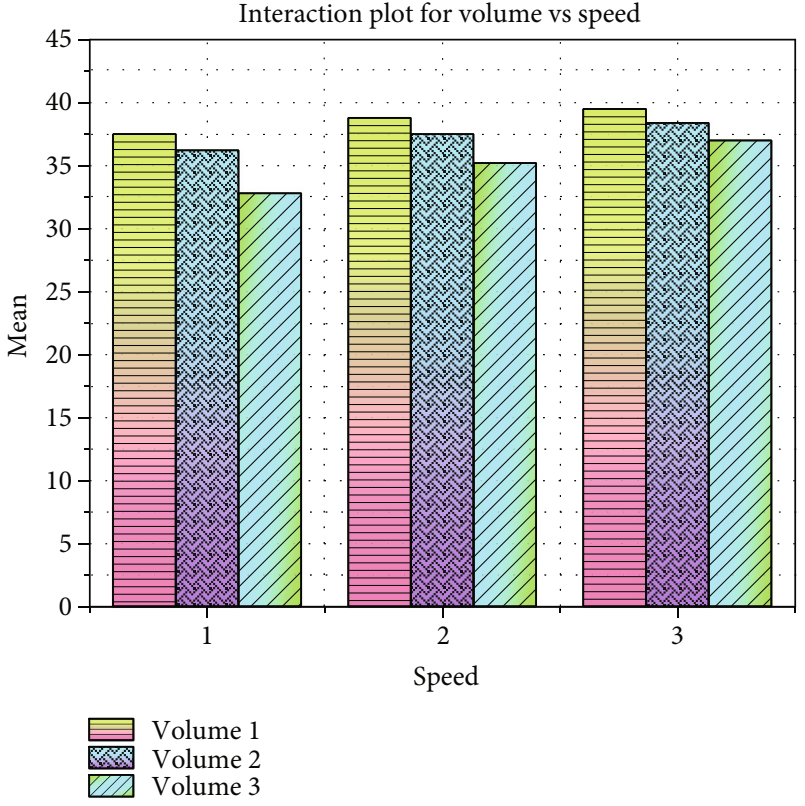

(b) Interaction plot for volume fraction vs. speed

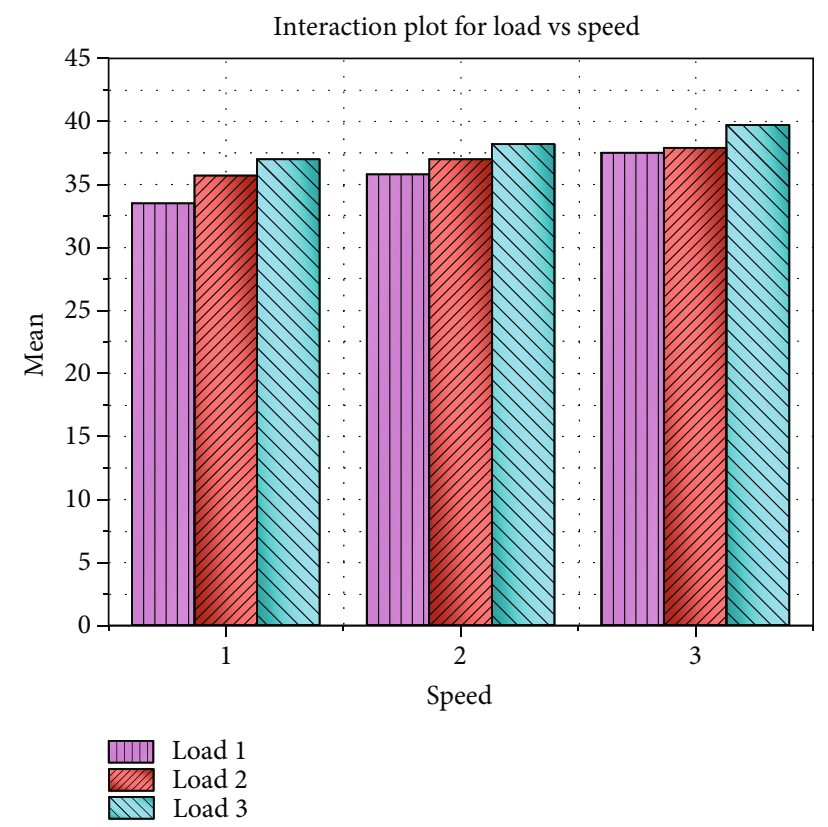

(c) Interaction plot for load vs. speed

Figure 4: Interaction plots for parameters $V, L$, and $S$.

TABLE 6: Confirmation test results.

\begin{tabular}{lccc}
\hline & \multirow{2}{*}{ Initial parameter } & \multicolumn{2}{c}{ Optimal parameter } \\
& & Prediction & Experimental \\
\hline Level & V2L2S2T2 & V3L1S1T1 & V3L1S1T1 \\
Wear $(\mu \mathrm{m})$ & 79.28 & & 70.12 \\
S/N ratio $(\mathrm{dB})$ & -37.82 & -29.978 & 37.99 \\
\hline
\end{tabular}

has improved from the starting condition to the optimal condition, resulting in a wear reduction of nearly $17 \%$. This is a huge step forward.
4.4. Wear Mechanism. Tribological testing of composites involves creating wear tracks to better understand the wear mechanism. Samples with three volume fractions of reinforcement: AA8011-7.5\% BN, AA8011-10\%BN, and AA8011-12.5\%BN, wear tracks have been created for each.

As a result, abrasive wear is the most common type of wear. In the micrographs, pits and prows can be seen, indicating that the adhesive has been worn away. As a result, it was determined that abrasive wear predominated, with certain evidence of excessive wear appearing in the overall microstructure study. 
The effect of four process parameters on the wear behavior of AA8011-BN particulate composites is being investigated. These parameters are mass fraction, normal load, sliding velocity, and time. In this experimental study, other variables such as heat treatment, temperature shifts, and reinforcing particle size are assumed to be constant. Future research on the effect of these other variables on AA8011BN's wear behavior is possible.

\section{Conclusion}

The wear performance of an AA8011-BN metal matrix composite is investigated using a Taguchi orthogonal array design with varying reinforcement content, applied force, sliding distance, and time. With a confidence level of 99 percent, this study found that the weight fraction is the most crucial factor affecting wear behavior in the specific test range. The applied force and sliding distance, which significantly impact wear behavior, are also important considerations. The wear property of the composite is unaffected by sliding time or parameter interaction. The researchers used Taguchi analysis to determine the best combination of fortified $w \mathrm{t} \%$, force, sliding velocity, and time for achieving the least amount of wear. The wear rate is reduced by nearly $17 \%$ from the initial condition to the ideal constraints. The findings of this study suggest that improving process parameters can lead to a more durable AA8011-BN composite for tribological applications. An abrasive wear mechanism predominates on worn surfaces, with some evidence of adhesion.

\section{Data Availability}

The data used to support the findings of this study are included in the article. Should further data or information be required, these are available from the corresponding author upon request.

\section{Conflicts of Interest}

The authors declare that there are no conflicts of interest regarding the publication of this paper.

\section{Acknowledgments}

The authors appreciate the supports from Wolaita Sodo University, Ethiopia. The authors thank Princess Nourah Bint Abdulrahman University, Saudi Arabia, and Presidency University, Bengaluru, for providing technical assistance to complete this experimental work. This study is supported by Princess Nourah Bint Abdulrahman University Researchers Supporting Project number (PNURSP2022R71), Princess Nourah Bint Abdulrahman University, Riyadh, Saudi Arabia.

\section{References}

[1] K. S. al-Rubaie, H. Goldenstein, and J. D. Biasoli de Mello, "Three-body abrasion of Al-SiC composites," Wear, vol. 225229, pp. 163-173, 1999.
[2] L. Li, Z. Han, M. Gao et al., "Microstructures, mechanical properties, and aging behavior of hybrid-sized $\mathrm{TiB}_{2}$ particulate-reinforced 2219 aluminum matrix composites," Materials Science and Engineering: A, vol. 829, p. 142180, 2022.

[3] X. Huang, J. Zhang, J. Miao, E. Cinkilic, Q. Wang, and A. A. Luo, "On the interactions between molten aluminum and high entropy alloy particles during aluminum matrix composite processing," Journal of Alloys and Compounds, vol. 895, p. 162712, 2022.

[4] M. Bai, Q. Xue, X. Wang, Y. Wan, and W. Liu, "Wear mechanism of SiC whisker-reinforced 2024 aluminum alloy matrix composites in oscillating sliding wear tests," Wear, vol. 185, no. 1-2, pp. 197-202, 1995.

[5] J. A. Jeffrey, S. S. Kumar, V. A. Roseline, A. L. Mary, and D. Santhosh, "Contriving and assessment of magnesium alloy composites augmented with boron carbide VIA liquid metallurgy route," Materials Science Forum, vol. 1048, pp. 3-8, 2022.

[6] V. Mohanavel, K. Rajan, and M. Ravichandran, "Synthesis, characterization and properties of stir cast AA6351aluminium nitride (AlN) composites," Journal of Materials Research, vol. 31, no. 24, pp. 3824-3831, 2016.

[7] J. Jeffrey, S. S. Kumar, P. Hariharan, M. Kamesh, and A. M. Raj, "Production and assessment of AZ91 reinforced with nano $\mathrm{SiC}$ through stir casting process," Materials Science Forum, vol. 1048, pp. 9-14, 2022.

[8] B. Venkataraman and G. Sundararajan, "The sliding wear behaviour of Al-SiC particulate composites-I. Macrobehaviour," Acta Materialia, vol. 44, no. 2, pp. 451-460, 1996.

[9] B. Venkataraman and G. Sundararajan, "The sliding wear behaviour of Al-SiC particulate composites-II. The characterization of subsurface deformation and correlation with wear behaviour," Acta Materialia, vol. 44, no. 2, pp. 461-473, 1996.

[10] A. M. Hassan, A. Alrashdan, M. T. Hayajneh, and A. T. Mayyas, "Wear behavior of Al-Mg-Cu-based composites containing SiC particles," Tribology International, vol. 42, no. 8, pp. 1230-1238, 2009.

[11] J. K. M. Kwok and S. C. Lim, "High-speed tribological properties of some $\mathrm{Al} / \mathrm{SiC}_{\mathrm{p}}$ composites: I. Frictional and wear-rate characteristics," Composites Science and Technology, vol. 59, no. 1, pp. 55-63, 1999.

[12] Y. Iwai, H. Yoneda, and T. Honda, "Sliding wear behavior of SiC whisker-reinforced aluminum composite," Wear, vol. 181-183, pp. 594-602, 1995.

[13] L. Rapoport, V. Leshchinsky, I. Lapsker et al., "Tribological properties of $\mathrm{WS}_{2}$ nanoparticles under mixed lubrication," Wear, vol. 255, no. 7-12, pp. 785-793, 2003.

[14] R. N. Rao and S. Das, "Effect of sliding distance on the wear and friction behavior of as cast and heat-treated Al-SiCp composites," Materials and Design, vol. 32, no. 5, pp. 3051-3058, 2011.

[15] S. C. Sharma, B. M. Girish, R. Kamath, and B. M. Satish, "Effect of $\mathrm{SiC}$ particle reinforcement on the unlubricated sliding wear behaviour of ZA-27 alloy composites," Wear, vol. 213, no. 1-2, pp. 33-40, 1997.

[16] R. N. Rao and S. Das, "Effect of matrix alloy and influence of $\mathrm{SiC}$ particle on the sliding wear characteristics of aluminium alloy composites," Materials and Design, vol. 31, no. 3, pp. 1200-1207, 2010.

[17] Y. Yalcin and H. Akbulut, "Dry wear properties of A356-SiC particle reinforced MMCs produced by two melting routes," Materials and Design, vol. 27, no. 10, pp. 872-881, 2006. 
[18] Z. Hasan, R. K. Pandey, and D. K. Sehgal, "Wear characteristics in Al-SiC particulate composites and the Al-Si piston alloy," Journal of Minerals and Materials Characterization and Engineering, vol. 10, no. 14, pp. 1329-1335, 2011.

[19] M. Singla, L. Singh, and V. Chawla, "Study of wear properties of Al-SiC composites," Journal of Minerals and Materials Characterization and Engineering, vol. 8, no. 10, pp. 813821, 2009.

[20] G. Taguchi, "Introduction to Quality Engineering, Tokyo," Asian Productivity Organization, vol. 4, no. 2, pp. 10-15, 1990.

[21] P. J. Ross, Taguchi Techniques for Quality Engineering: Loss Function, Orthogonal Experiments, Parameter and Tolerance Design, McGraw-Hill, New York, 2nd edition, 1996.

[22] D. C. Montgomery, Design and analysis of experiments, John Wiley \& Sons Inc., New York, 2001.

[23] R. A. Fisher, The design of experiments, Ronald A. Fisher, Oliver \& Boyd, 5th edition, 1951. 